\title{
O COMÉRCIO JUSTO E O COOPERATIVISMO COMO PRÁTICAS DE SUSTENTABILIDADE SOCIO-ECONÔMICA: UM ESTUDO DE CASO EM BREJINHO
}

\author{
Geiziane Costa Nascimento \\ Graduada em Tecnologia em Comércio Exterior pelo Instituto Federal de \\ Educação, Ciência e Tecnologia do Rio Grande do Norte. Curso de Formação de \\ agentes de Comércio exterior e o $1^{\circ}$ Exportação (MDIC), Recepcionista de \\ empresa/Auxiliar de Escritório (PROJAP). Certificação Profissional em \\ Informática (News Center Informática). E-mail: geiziane.costa@ hotmail.com \\ Érika Araújo da Cunha Pegado \\ Graduada em Licenciatura em História pela Universidade Federal do Rio Grande do Norte \\ (1990), graduação em Bacharelado em Direito pela Universidade Federal do Rio Grande \\ do Norte (1997) e mestrado em Engenharia de Produção pela Universidade Federal do Rio \\ Grande do Norte (2004). Professora do IFRN. \\ Email: erika@cefetrn.br
}

\section{RESUMO}

A globalização proporcionou grandes transformações em diversas modalidades, entre elas o setor produtivo dos países. Diante disso, enfoca-se o Fair Trade, prática que partiu da realidade causada pela globalização, com a finalidade de trazer para os pequenos produtores sustentabilidade socioeconômica. Os quais, geralmente, são estabelecidos em cooperativas ou associações, uma vez que atende as exigências do comércio justo. Com isso, este trabalho tem como principal objetivo verificar os benefícios socioeconômicos que o comércio justo pode originar para os pequenos produtores da farinha de mandioca na cidade de Brejinho do Rio Grande do Norte, além das vantagens proporcionadas para o comércio exterior do estado. Descrevendo teoricamente, o comércio justo no âmbito da globalização, suas exigências legais e o impulso das empresas que trabalham com responsabilidade social. Assim, metodologicamente fez-se o uso descritivo dos dados coletados por meio de uma entrevista tendo como instrumento de dados um questionário, voltado para pequenos produtores da farinha situados na cidade estudada, analisando uma possível aplicabilidade do comércio para desenvolver o setor farinheiro. Diante da avaliação conclui que tal setor tem capacidade de aderir o comércio justo, o qual possibilitará um desenvolvendo no quadro socioeconômico da cidade, tendo em vista que necessitará de alguns reajustes no quadro trabalhista. No que tange o comércio exterior, o produto já consta na balança comercial brasileira, logo dependendo do grau de interesse dos produtores o setor trabalhado a partir do comércio justo podem chegar atender a tais expectativas para a economia do estado.

PALAVRAS-CHAVE: fair trade, cooperativismo, produção de farinha de mandioca

\section{THE TRADE FAIR AND COOPERATIVE AS PRACTICE OF SOCIO- ECONOMIC SUSTAINABILITY: A CASE STUDY IN BREJINHO}

\begin{abstract}
Globalization has brought great changes in various ways, including the productive sector of the countries. Thus, focusing on the Fair Trade, practice that part of reality caused by globalization, aiming to bring small producers socioeconomic sustainability. Which usually are set in cooperatives or associations, as it meets the requirements of fair trade.
\end{abstract}


Therefore, this work has as main objective to verify the socioeconomic benefits that fair trade can lead to small producers of cassava flour in the city of Brejinho Rio Grande do Norte, in addition to the benefits offered to the foreign trade of the state. Theory describing the trade fair in the context of globalization, their legal requirements and boost the companies that work with social responsibility. Thus, methodologically it was the use of descriptive data collected through an interview with the instrument of data a questionnaire, directed to small producers located in the city's flour studied, analyzing the possible applicability of the trade sector to develop the pudding. Given the evaluation concludes that sector is able to join the trade fair, which will develop an economic framework in the city in order to need a few adjustments under Labor. As regards foreign trade, the product is already in the Brazilian trade balance, just depending on the degree of interest of producers from the sector worked in trade fair can come to meet such expectations for the economy of the state.

KEY WORDS: Fair Trade, Cooperativism, Production of Cassava flour.

\section{O COMÉRCIO JUSTO E O COOPERATIVISMO COMO PRÁTICAS DE SUSTENTABILIDADE SOCIO-ECONÔMICA: UM ESTUDO DE CASO EM BREJINHO}

\section{INTRODUÇÃO}

Atualmente o comércio vem apresentando diversidades na sua formação, isso na maioria das vezes, é decorrente do grande avanço que a globalização trouxe ao mundo, onde não só o comércio mudou, mas também áreas como a política, a educação, a saúde, bem estar social entre outros.

Porém apesar das modificações ocorridas ao longo do tempo ainda encontra-se grupos de pessoas que não tiveram ou não tem oportunidade de melhorar suas condições socioeconômicas. Com isso surge o comércio justo (Fair Trade), comércio esse que desenvolve ao longo do seu curso mecanismos de valorizar o trabalho de pequenas comunidades que se encontram em desvantagens no âmbito socioeconômico.

Com o apoio de algumas entidades, na maioria das vezes não governamentais, os pequenos produtores são conscientizados e orientados a aderir à prática deste comércio. Normalmente eles são organizados em cooperativas ou associações para formalizar a comercialização, produzindo mercadorias ecologicamente corretas, melhorando as condições de trabalho, oferecendo salários justos e respeitando os aspectos legais do país aderente.

No âmbito do que já foi ponderado, surge como problemática à seguinte indagação: como o comércio justo (Fair Trade) pode beneficiar o quadro socioeconômico dos pequenos produtores de farinha de mandioca na cidade de Brejinho localizada no RN e também o comércio exterior do estado?

Contudo, o presente trabalho caracterizou-se metodologicamente como uma pesquisa exploratória descritiva. Pois, Oliveira e Filgueira (2004, p. 2009) asseveram que, "a pesquisa é um conjunto de procedimentos sistemáticos, baseados no raciocínio lógico que 
tem por objetivo encontrar soluções para problemas propostos, mediante a utilização de métodos científicos".

É importante relatar também que a pesquisa está delimitada em um estudo de caso com coleta de dados primários, mas também se buscou informações secundárias para dar suporte à resposta da problemática levantada, este foi voltado para os produtores de farinha de mandioca como já comentado.

Além disso, a investigação é dada quantiqualitativa, uma vez que os dados coletados foram estudados para analise do discurso, contendo estudos numéricos e teóricos. No que tange a coleta dos dados o instrumento utilizado foi um questionário aplicado em campo, o qual se constituiu de perguntas abertas e fechadas para dar suporte à entrevista.

O presente trabalho é de grande relevância para a vida pessoal, profissional e acadêmica da autora, onde a princípio este tema foi escolhido a partir de um interesse próprio de se criar uma prática produtiva mais bem elaborada na cidade de Brejinho. Pois seu principal segmento produtivo é a farinha de mandioca já reconhecida como a melhor farinha do estado, além destes aspectos o estudo proporciona um grau de conhecimento expressivo na formação acadêmica.

\section{FAIR TRADE DIANTE DA GLOBALIZAÇÃO}

A globalização destacou-se mais após a queda do muro de Berlim, proporcionando maiores negócios entre as nações e ocasionando crescimento econômico principalmente nos países mais desenvolvidos. Diversos teóricos, sobretudo sociólogos, define esse paradigma como um fenômeno aliado a aspectos econômicos que internacionaliza o mundo, além apresentar prodígios do campo social tendo como fator principal a influencia cultural dos povos.

Todavia, nem toda população teve o privilégio de acompanhar esse desenvolvimento, ou se acompanha está sentindo as conseqüências negativas do fenômeno. Pois a globalização gera desigualdade social, uma vez que faltam postos de trabalho, bem-estar social, educação, respeito humano etc.

Diante disso, surgiu um movimento denominado de Comércio Justo (Fair Trade) criado na maioria dos casos por Organizações não Governamentais (ONG's), o qual é apontado como mais um mecanismo promissor para o comércio exterior entre as nações. A International Federation for Alternative Trade, (2001 apud VERENHITACH, 2006) assegura que:

Este se consiste em uma parceria comercial baseada em diálogo, transparência e respeito, que busca maior eqüidade no comércio internacional. Ele contribui para o desenvolvimento sustentável através do oferecimento a produtores marginalizados de melhores condições de troca e maiores garantias de seus direitos.

Essa prática teve início na Europa entre as décadas de 1940 a 1950 por iniciativas religiosas com caráter filantrópico, com o objetivo de vincular pequenos produtores pobres no mercado europeu, notando-se assim um comércio solidário e ético. Em 1970 já havia atividades semelhantes a este comércio, realizando vendas de produtos que em sua 
produção respeitava os direitos humanos e o meio ambiente, oferecendo produtos ecologicamente corretos, ressalva Schneider (2007).

Esta prática tem como finalidade desenvolver a sustentabilidade econômica, sociais e ambientais de uma comunidade que não detém uma economia estimável. Neste contexto os produtores recebem uma remuneração através de preços justos, garantindo uma vida mais digna e segura. Procurando proporcionar cadeias produtivas que se enquadrem às exigências legais e ecológicas, formando assim cooperativas dentro de comunidades que possui uma economia desfavorável.

Diante destes aspectos, as organizações que caminham dentro do legal estão cada vez mais atingindo um ranking privilegiado no mercado, pois nos Estados unidos, por exemplo, a população é conhecida por consumidores verdes (green consumers) devido darem credibilidade aos produtos confeccionados por empresas que se comportam com um caráter ecologicamente correto (SCHMITT; LEISINGER, 2001).

Logo, os produtos certificados pelo comércio justo destinados aos consumidores conscientes tendo um preço justo e um grau de qualidade excelente, vêm ganhando espaço no mundo, principalmente na Europa. Como requisitos para adentrar no mercado com o selo de Fair Trade é necessário que se implemente as práticas que garantem a adequação desta na organização. Estes princípios podem ser observados a seguir, baseados em Fretel e Simoncelli-Bourque (2003):

a) A transparência e a co-responsabilidade na gestão da cadeia produtiva, de distribuição e comercialização;

b) A relação de longo prazo na qual o comprador oferece treinamento e outras formas de apoio necessário aos produtores, além do acesso às informações do mercado;

c) Os produtores devem estar democraticamente organizados em cooperativas ou associação;

d) O ambiente de trabalho deve ser seguro,

e) As crianças devem estar freqüentando a escola;

f) O meio ambiente tem que ser respeitado;

g) A igualdade de gêneros, etc.

O Fórum de Articulação de Comércio Ético e Solidário do Brasil (FACES) constatou por meio destes dados conclui-se maior parte dos produtos comercializados por estas regiões são os setores agropecuário, pesqueiro e extrativista, alimentício e artesanal. Além disso, de acordo com Julião (2008) os principais mercados compradores são os Estados Unidos da América, o Reino Unido, a Suíça, a França e a Alemanha.

Nos países aderentes desta prática se encontra a certificação de associações que orientam os produtores para expandirem seus negócios, as quais são a European Fair Trade Association (EFTA), International Federation for Alternative Trade (IFAT), Fair Trade Federation (FTF), e o Fairtrade Labelling Organizations International (FLO). A IFAT é a associação que mais certifica produtos no Fair Trade. 


\section{NORMAS BRASILEIRAS QUE PERMEIAM O COMÉRCIO JUSTO}

Para que uma organização venha a adotar o comércio justo é necessário se adequar as normas postas por este comércio, tendo em vista que sua certificação precisa garantir a inexistência da prática ilegal, onde todos devem acorda os princípios e procedimentos fundamentais para a obtenção de uma relação comercial mais justa.

Uma das exigências criadas é a formação de cooperativas ou associações para se criar bloco produtivo. Os produtores que praticam o comércio justo geralmente são formados por cooperativas para dar suporte aos objetivos deste comércio, essas atividades econômicas estão designadas por sociedades civis, as quais não entram em concordata. Esta atividade é realizada por todos os vinculados ao comércio, onde nomeia um para tomar de conta dos aspectos legais e gerenciais.

A Consolidação das Leis do Trabalho (CLT), em sua lei 5. 452 se estabelece em seu Art. $2^{\circ}$ que (BRASIL, 1943):

a) Considera-se Cooperativa de Trabalho a sociedade constituída por trabalhadores para o exercício de suas atividades laborativas ou profissionais com proveito comum, autonomia e autogestão para obterem melhor qualificação, renda, situação socioeconômica e condições gerais de trabalho.

b) $\S 1^{\circ}$ A autonomia de que trata o caput deste artigo deve ser exercida de forma coletiva e coordenada, mediante a fixação, em Assembléia Geral, das regras de funcionamento da cooperativa e da forma de execução dos trabalhos, nos termos desta Lei.

c) $\S 2^{\circ}$ considera-se autogestão o processo democrático no qual a Assembléia Geral define as diretrizes para o funcionamento e operações da cooperativa, e os sócios decidem sobre a forma de execução dos trabalhos, nos termos da lei.

É importante mencionar que as cooperativas inicialmente podem dar início ao negócio com a quantia que cada membro pode disponibilizar. Além disso, elas podem ser formadas pelo número mínimo de associados de 20 (vinte), conforme (BRASIL, 1971) o art. $6^{0}$ da Lei ${ }^{\circ}$ 5.764, de 1971, ressaltando-se que as cooperativas singulares não podem ser constituídas exclusivamente por pessoas físicas, nem, tampouco, por pessoa jurídica com fins lucrativos ou com objeto diverso das atividades econômicas da pessoa física.

(BRASIL, 1990) na lei $\mathrm{n}^{\circ}$ 8.069, outra questão relevante é o respeito com o Estatuto da Criança e do Adolescente, uma vez que tem um grande cuidado em garantir o bem-estar das crianças. Onde elas podem desenvolver produtos, desde que não sejam prejudicados no que diz respeito a sua educação, seu bem estar social e sua segurança.

Em seu art. 60 ela prescreve que é proibido qualquer trabalho a menores de dezesseis anos de idade, pois de 16 a 18 o adolescente tem que desenvolver uma atividade que seja para seu crescimento profissional, denominada pelo governo de não penosa. Isso passa a ser um grande diferencial para os produtores, pois ainda existe exploração infantil no mundo. Onde algumas empresas, mesmo que de forma indireta, consolidam aos seus empregados crianças ou adolescentes, anulando assim as oportunidades que elas poderiam ter ao longo desta fase. A criança que trabalha quase sempre o faz em detrimento da escola, o que gera 
um adulto com baixa qualificação e que encontrará maiores dificuldades de competir no mercado de trabalho. (SANTOS, 2002, apud CUSTÓDIO, 2005, p. 194)

(BRASIL, 1977) Na Lei $\mathrm{N}^{\circ}$ 6.514, a qual trata da segurança e medicina do trabalho, estabelece em seu art. 166 que toda empresa é obrigada a fornecer aos empregados, gratuitamente, equipamento de proteção individual adequado a cada atividade e em perfeito estado de conservação e funcionamento, sempre que as medidas de ordem geral não ofereçam completa proteção contra os riscos de acidentes e danos à saúde dos empregados.

A preocupação com meio ambiente é mais um fator a ser tomado pelos produtores, tendo em vista que as decisões tomadas para a compra e administração das matérias-primas empregadas na produção não pode provocar danos ao meio ambiente. Pois a aquisição destas é que mais provoca acidentes no campo ambiental, com isso no comércio justo se faz com o objetivo de manter o equilíbrio na natureza.

\section{PARTICIPAÇÃO DAS EMPRESAS SOCIALMENTE RESPONSAVEIS}

Atualmente percebe-se o consumidor final está cada vez mais preocupado com o modo em que as mercadorias são produzidas, e também as condições de trabalho e social dos fabricantes deste. Isso vem expandindo e interferindo no comércio de empresas que não dão tanta importância a aspectos como estes que se tornam fundamentais durante a produção.

Além disso, em alguns casos os consumidores exigem o comprometimento com o meio ambiente por parte das empresas, uma vez que o homem está mais consciente da realidade ambiental a que se assiste mundialmente.

Com isso está se criando uma nova cultura por parte da sociedade em conservar e desenvolver práticas que contribua analogamente para o meio ambiente e os cidadãs. Darcanchy (2006) afirma que "no cenário mundial já existem inúmeras iniciativas empresariais que envolvidas em projetos sociais, buscam o desenvolvimento da cultura da responsabilidade social."

No âmbito do comércio exterior, iniciativas como estas podem atrair potenciais importadores, pois a percepção do consumidor estrangeiro diante de tais aspectos é bastante promissora. Os quais adquirem produtos com qualidade agregando valor social, logo eles sentem-se satisfeito com a compra realizada.

Já em relação às organizações que estão obedecendo às normas ambientais, como é o caso do Fair Trade, consegue diante disso torna-se competitiva entre as demais organizações. A partir deste cenário elas obtêm crescimento em sua margem de lucro, uma vez que cada produtor ganha uma remuneração mais justa.

O papel da economia contemporânea é inserir os ativos ambientais no processo de negociações, para garantir a sobrevivência das espécies e os direitos das futuras gerações. Esses instrumentos, entre outras, têm estas finalidades, pois buscam assegurar o uso 
disciplinado do meio ambiente e resguardar os interesses de seus entes (MOTA, 2006, p. 172).

Em contradição a esta realidade, diversas indústrias no mundo estão produzindo sem pensar no meio ambiente, por mais que estejam sendo constantemente advertidas das implicações que estão provocando no mundo e ainda tomam o espaço daquelas que agem corretamente, uma vez que oferecem produtos com baixa qualidade, causando danos ao consumidor. É importante salientar que muitos países fazem movimentos quanto à preservação do meio ambiente, construindo idéias excelentes, mas na pratica suas atitudes são diversas aos conceitos que defendem.

Vieira (2000, p. 95) afirma que, "das emissões anuais de gases causadores do efeito estufa, 75 a $80 \%$ foram provenientes dos países industrializados, que representam menos de $20 \%$ da população mundial." Porém atualmente a falta de transparência nos negócios não prejudica apenas clientes e consumidores, mas também a própria empresa, uma vez que é descoberta a omissão feita por esta quanto às práticas sociais e ambientais.

De acordo com Ribeiro e Souza (2008), as organizações estão inquietadas em adotar técnicas estratégicas para responsabilidade social, com o objetivo de acompanhar as mudanças globais. Diante disso fica claro que iniciativas como o Fair Trade pode ser uma propulsora para produtores conseguir expandir seus negócios e conseqüentemente desenvolver a sociedade.

São aspectos como esse que definem os acordos entre os países, uma vez que os importadores estão também preocupados com as condições em que os produtos são confeccionados pelos exportadores. Dependendo das práticas éticas eles firmam seus negócios.

Tendo em vista que a partir do momento em que o empresário começa a atender aos princípios legais e éticos eles vão ganhando credibilidade no mercado. Pegado (2007) assegura que, "o cumprimento da normatização ambiental é fator de extrema importância na análise da competitividade das empresas que atuam no comércio exterior".

\section{ANÁLISE DOS DADOS}

A prática de comércio justo é voltada para o beneficiamento de uma região que estar em desvantagem social e econômica em relação a alguns lugares desenvolvidos. Geralmente ela é desenvolvida com o apoio de ONGs tendo a finalidade de aproximar os pequenos produtores e comunidades do mundo globalizado, além de tornar uma pequena economia local numa economia forte no estado e até no país. E, dependendo dos princípios preservados pelos produtores chegar ao mercado exterior certificada pelo Fair Trade.

Logo, este estudo vem com o intuito de explorar uma região para aderir à prática do Fair Trade, ao analisar a produção de farinha de mandioca no estado para ampliar o comércio desta, uma vez que o produto se faz presente na refeição da maior parte da população brasileira. 
Diante disso, tem-se como foco a produção da melhor farinha de mandioca do Rio Grande do Norte que fica localizada em Brejinho no nordeste brasileiro, tendo uma distância aproximada a $57 \mathrm{~km}$ da capital, realizado por meio das rodovias pavimentadas BR-101 e $\mathrm{RN}-002$, ver figura 1. Contudo, o nome Brejinho está ligado aos pequenos brejos que existiam na região, o qual no início Câmara Cascudo denominou o município de Abrejava, nome do olho d'água que formava os brejos.

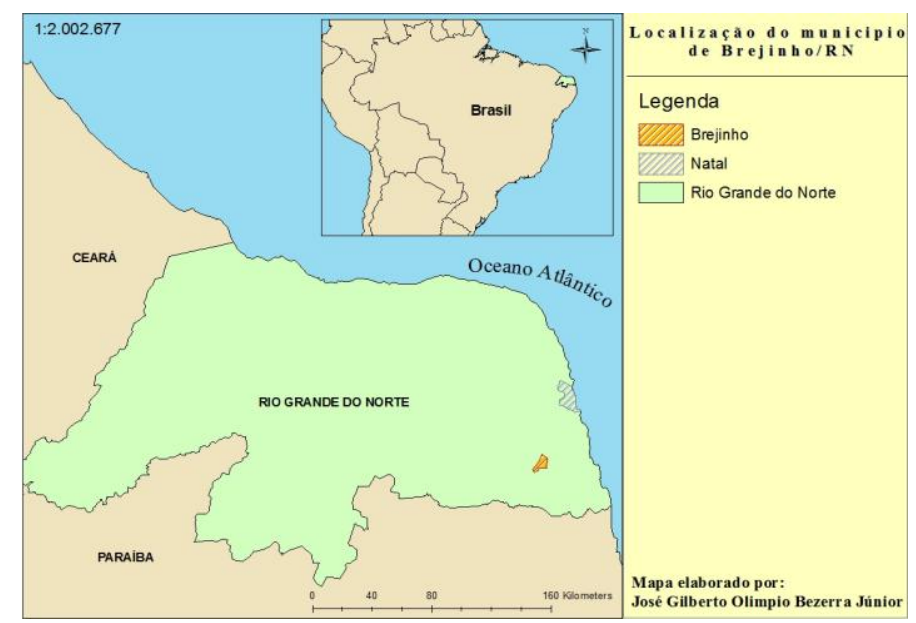

Figura 1: Mapa do Rio Grande do Norte

De acordo com o Instituto Brasileiro de Geografia e Estatística (2008) em 2007 estimou-se uma população de 11.135 brejinenses na cidade. Já referente ao comércio local dado no inicio, os mais relevantes foi o setor agrícola, coco, cana-de-açúcar, frutas tropicais e mandioca. Este último torna-se o principal insumo do setor produtivo no povoado, tendo uma qualidade superior em todo o estado potiguar conhecida como "farinha de Brejinho".

Atualmente a economia da cidade está ligada a farinha de mandioca e a produção de laticínios, este último induziu a criação de bovinos na região, no qual muitos agricultores também são fornecedores de leite a empresa laticínios. Esta vem se destacando no mercado e também gerando emprego para a região, além destes existe o comércio do feijão verde e a batata doce.

Quanto o comércio da farinha de mandioca, ela é uma atividade produtiva bastante permanente na economia da comunidade, que há anos vêm se fortificando através de novas tecnologias e procedimentos. Outro segmento que também tem representatividade é o serviço, a partir disso os setores que compõe o PIB de Brejinho podem ser diagnosticados no gráfico a seguir, de acordo com o Conselho Nacional dos Municípios (CNM): 


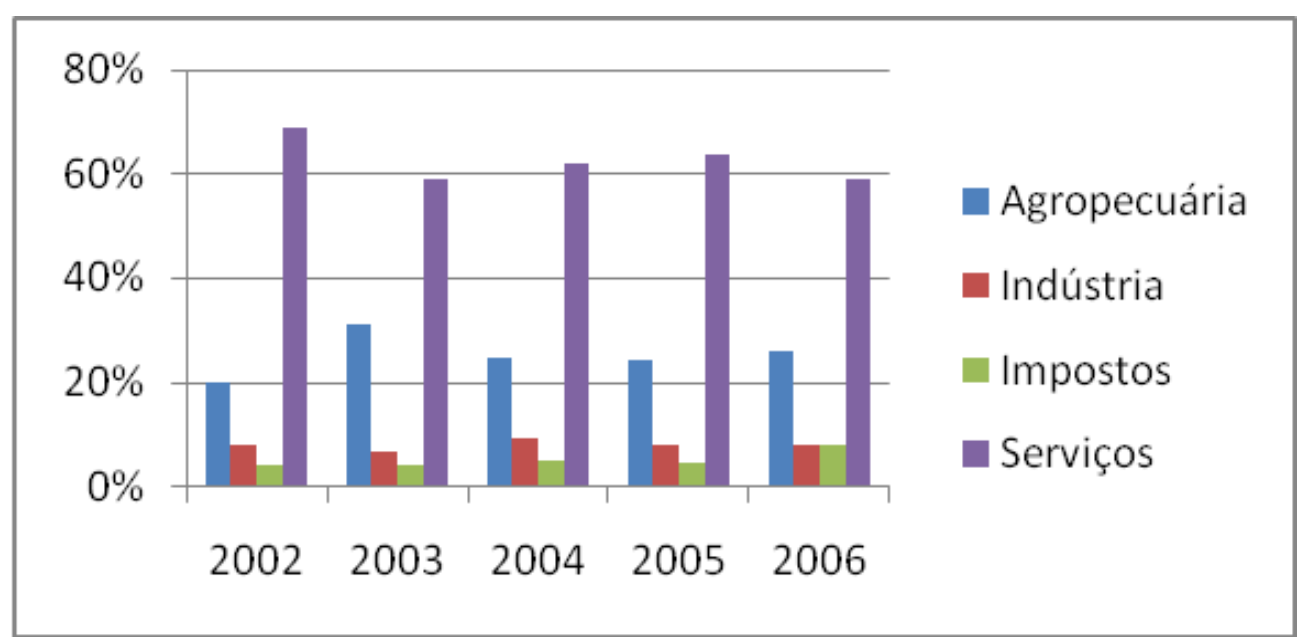

\section{Gráfico 2: Composição do PIB de Brejinho/RN}

A partir deste gráfico, percebe-se que a agropecuária ainda possui é relevância na região, ficando atrás da esfera de serviços. Em 2003 houve um aumento de $11 \%$ no setor agropecuário, ficando com $31 \%$ no PIB da cidade, porém em 2006 se tem um quadro de $26 \%$ deste, deixando a entender que há uma oscilação, mas sem nenhuma alteração espantosa.

No que tange a produção de farinha, percebe-se por meio do gráfico 3, que se encontra abaixo, que as fábricas de farinha estão cada vez mais se legalizando. Onde, mais de $50 \%$ das fábricas diagnosticadas possui uma firma aberta, assemelhando-se assim com aspectos do comércio justo, o qual busca cada vez mais aderir às normas legais brasileiras, valendo ressaltar que esse quadro se dá também pelas exigências governamentais.

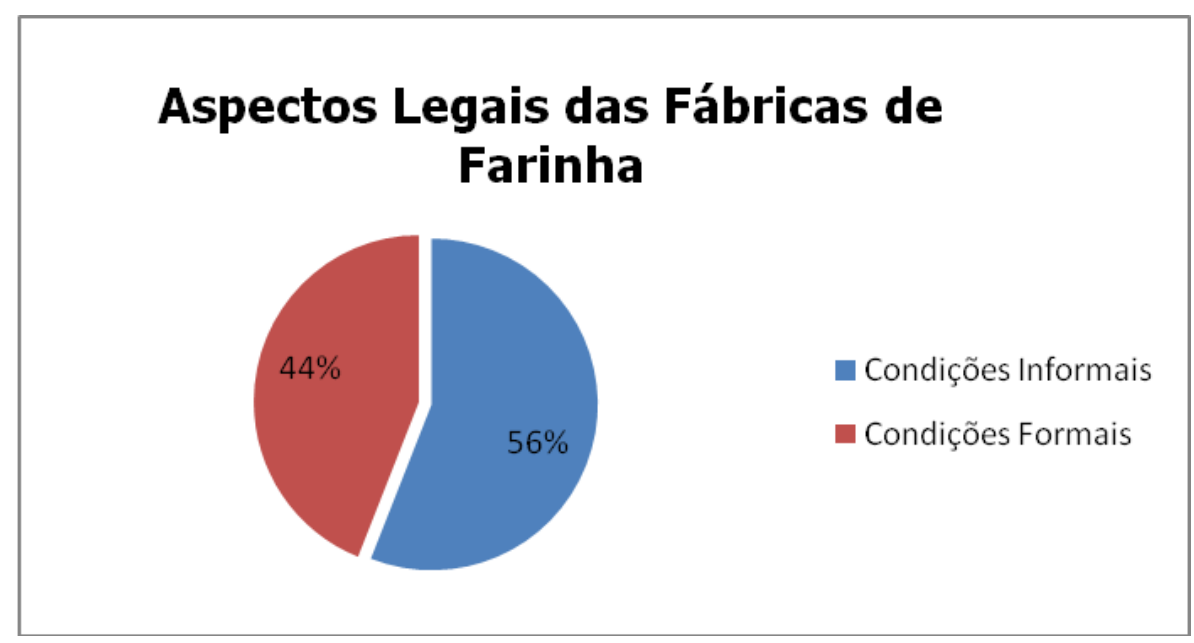

Gráfico 3: Panorama Legal das Fábricas

Porém existem produtores que não estão dentro das normas legais, devido às condições financeiras que possuem, tornando-se assim pequenos produtores na região. Com isso, eles alcançam apenas o mercado local, onde os principais clientes são os produtores mais fortes no mercado que agem como consumidores intermediários, e eles acabam ficando em desvantagem. 
Os produtores entrevistados afirmaram que o comércio está muito difícil, onde a tendência é acabar com a produção. Pois alguns estão atualmente diminuindo sua produção por não compensar financeiramente, principalmente os que possuem pouca participação no comércio de farinha.

Examina-se que a maioria dos fabricantes estão ligados aos negócios de farinha desde a década de 1970, onde apenas três fábricas ficaram numa faixa de 2 (dois) a 6 (seis) anos, e as outras estão acima de 23 (vinte e três) anos. É importante mencionar que algumas delas foram deixadas por heranças para os produtores atuais.

Segundo alguns entrevistados o segmento da farinha precisa de políticas publicas para que houvesse um incentivo a mais, pois deixaram claro que os políticos da cidade não apresentam interesse pelo setor.

Logo, se existisse um apoio as fábricas de farinha da cidade poderiam ganhar mais espaço no mercado, fomentando a economia, além de trazer boas perspectivas produtivas e financeiras para os fabricantes. Importante ressaltar que a participação em feras é um mecanismo promissor para a divulgação do produto. Um exemplo claro é a feira do empreendedor que é patrocinado pelo SEBRAE do estado, onde possibilita a divulgação e comercialização do produto.

No que tange o quadro empregatício das fábricas pesquisadas, o seguimento estudado só emprega $1,33 \%$ da população da cidade, tal aspecto pode está explicitado no gráfico 5.

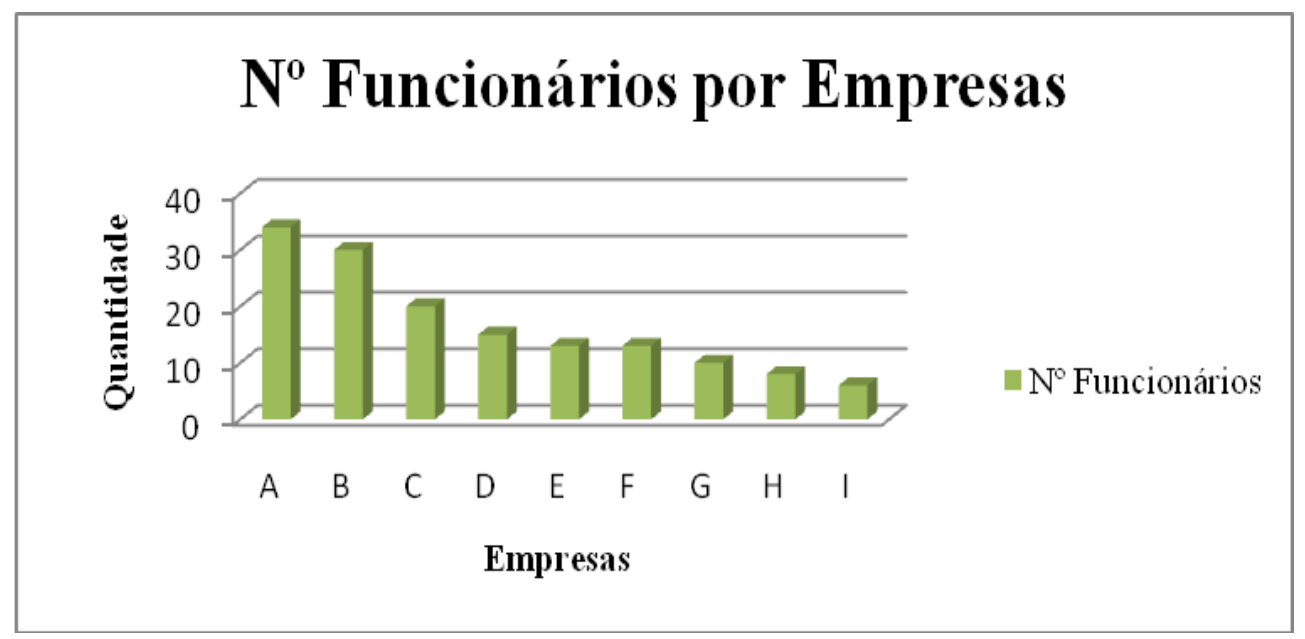

Gráfico 5: Quadro de Funcionário

Neste gráfico pode-se diagnosticar, através de uma escala, que as empresas pesquisadas apresentam um percentual muito baixo no quadro de funcionários, entendendo assim que não existe uma participação significativa da população na. De acordo com alguns entrevistados, isso se dar pelos Bolsas Famílias criados pelo governo, os quais vem provocando a falta de interesse por um trabalho como este.

Além disso, diante de todos os entrevistados, apenas duas pessoas tem a carteira assinada, as quais trabalham possuem uma função relevante dentro da hierarquia empresarial. Por estes motivos é que o setor está cada vez mais se industrializando, como por exemplo, já 
existe um equipamento processar a raspagem da farinha, porém não apresenta o mesmo grau de qualidade quando desenvolvido manualmente.

Interessante ressaltar que entre estes funcionários apenas uma casa de farinha se utiliza dos serviços de adolescentes, onde as outras não oferecem trabalhos para estes devido às exigências legais. Pois segundo um dos respondentes alguns anos atrás havia crianças junto às mulheres que faziam o processo da raspagem da mandioca, devido não ter quem cuidasse delas e não podiam deixá-las sozinhas.

Porém este quadro hoje já pode ser suprido, uma vez que existem na cidade assistências sociais, como por exemplo, o Programa de Erradicação do Trabalho Infantil (PETI) e as creches para oferecer lazer e educação às crianças, deixando assim de estar no ambiente de trabalho dos pais ou na rua.

Superior Tribunal de Justiça (STJ) apresenta uma decisão em ação civil pública com o objetivo de assegurar creche para crianças de 0 a 6 anos, com fundamento do dever constitucional do Estado e no direito subjetivo da criança (SILVA, 2007, p. 68).

Importante mencionar que a maior parte destes funcionários é composta por mulheres, devido à necessidade do processo de raspagem da mandioca, pois se soma 104 mulheres empregadas no ramo, uma vez que elas têm uma fácil habilidade para desenvolver tal atividade.

Além disso, elas trabalham por produção e também não são consideradas como funcionárias fixas, tendo em vista que em alguns casos a fabricação acontece em dias alternados, e às vezes duas vezes na semana.

Esse cenário pode ser priorizado com a prática de comércio justo, uma vez que um dos princípios da tal prática é a igualdade de gêneros, onde o trabalho das mulheres é valorizado e recompensado corretamente.

Diante do posicionamento dos respondentes, as pessoas que portam necessidades especiais não fazem parte destes dados por não terem idoneidade de desenvolver um serviço dentro de uma casa de farinha. Referente aos homens, os dirigentes destas casas contrata-os verbalmente para conduzir o processo da farinha, os quais começam desde a busca da mandioca no lugar designado pelo fornecedor até o empacotamento e na venda final.

Outro aspecto de extrema importância é a necessidade de incorporar os equipamentos de segurança para melhorar as condições de trabalho dos empregados, pois o serviço, principalmente das mulheres, é perigoso devido se utilizarem de facas afiadas que pode machucar as mãos. Além disso, o uso de objetos que combata os ruídos ocasionados pelas maquinas produtivas são essenciais para não provocar danos na audição dos funcionários.

Também é preciso que as casas de farinha se adéqüem as normas de segurança, uma vez que trabalha com máquinas, temperatura dos fornos, tendo em vista também a necessidade de adquirir equipamentos higiênicos, pois no processo de empacotamento o funcionário tem que ter proteção para manter o controle de qualidade e também evitar danos a saúde deste.

No âmbito de tal processo é interessante descrevê-lo, pois este é desenvolvido a priore pela colheita que é feita quando a mandioca (raiz da planta) está com dezesseis a vinte meses, 
no intervalo de abril a agosto, que é a época da sazonalidade do produto, uma vez que tem um rendimento máximo.

Todavia, fora deste períodos por mais que a farinha seja produzida com uma boa qualidade, não atinge o mesmo volume de produção na sua sazonalidade, pois a matéria prima apresenta mais manipueira ${ }^{1}$ que massa. Vale ressaltar que após a colheita ela deve ser utilizada em um prazo máximo de 36 horas, para não haver escurecimento, perdas ou queda na qualidade, pois depois da ceifa da matéria-prima entra em processo de fermentação. O próximo passo é a lavagem para retirar a terra prendida a casca, e daí passa para a raspagem, a qual é realizada manualmente utilizando uma faca afiada, estas primeiras etapas bem desenvolvidas resultam a qualidade da farinha.

Depois disso, é necessário moer a mandioca em um cilindro com o objetivo de triturar o produto e a partir daí espremida, reduzindo o máximo sua umidade, a qual se destina em seguida para a peneiragem desta levando para o forno com a finalidade de suprimir toda a água da massa obtendo a farinha, que será pesada e empacotada para sua venda, classificando-a de grossa ou fina, amarela ou branca. Para maiores detalhamento referente ao processo consultar o site (www.emater.mg.gov.br), analisar a figura 2:

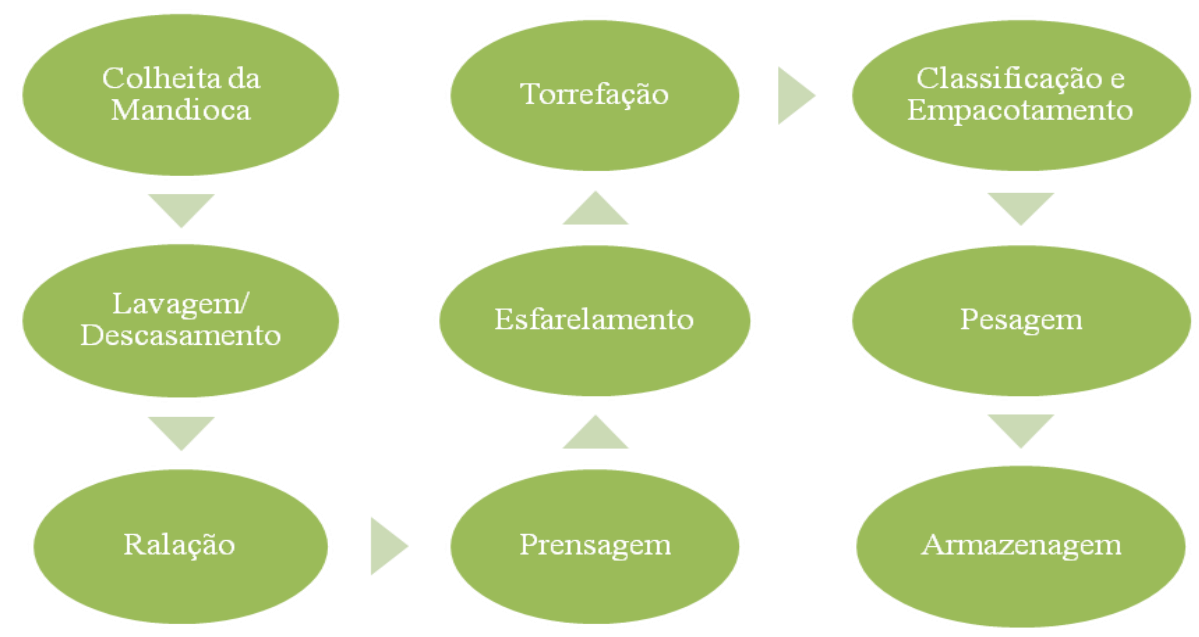

Figura 2: Fluxo do Processamento da Farinha

Com relação ao impacto ambiental que esse processo pode acarretar, ele pode ser o mínimo o possível quando todos os resíduos são aproveitados, diante disso, apenas $2 \%$ dos respondentes declararam não reaproveitar todos os vestígios. Tais detritos são: a manipueira, a casca da mandioca, a crueira e a cinza.

Diante da pesquisa ficou claro que a manipueira é utilizada como suplemento alimentar junto à casca para os bovinos ou também como adubo vegetal, tendo em vista que ela é muito tóxica e poluente, prejudicando o lençol freático e a saúde da população que residir próxima, devido ter um aroma muito intenso. Logo, a maioria dos produtores de farinha vende ou doa para os fazendeiros da região, além disso, um dos entrevistados ressaltou que a EMATER promoveu um evento na cidade, oferecendo mini-cursos para o uso da farinha e seus resíduos, onde aprenderam a fazer sabão higiênico com a manipueira, porém

\footnotetext{
${ }^{1}$ O líquido de cor amarelada resultante da prensagem da massa ralada.
} 
segundo ele não compensava desenvolver o produto, ou não iria ter aceitabilidade no comércio.

Já de acordo com o Sebrae (2008)

[...] dela pode ser utilizados como vários produtos: como fertilizante natural; substituindo os agrotóxicos nas lavouras; como defensivo contra insetos e pragas, como formigas e doenças que atacam as lavouras; na produção de vinagre para uso doméstico e comercial; na produção de tijolos e na produção de sabão. Tendo em vista que ela é rica em vários nutrientes como Potássio (K), Nitrogênio (N), Magnésio (Mg), Fósforo (P), Cálcio (Ca) e Enxofre (S), utilizada também para a fertilização do solo e de folhas.

Os produtores que não faz uso da manipueira declararam que não estão aproveitando devida sua incapacidade financeira, pois é preciso que seja armazenada em um lugar adequado. Contudo, ela fica apenas no reservatório até o dia em que é esgotada, jogando ao ar livre sem nenhuma utilização.

Já a casca de mandioca é destinada para os animais domésticos da classe dos bovinos, caprinos e ovinos. No caso dos bovinos, os fazendeiros que possuem vacarias, para fornecer leite à fábrica de laticínios da cidade, estão sempre comprando, pois é um suplemento alimentar que faz aumentar a produção de leite.

Quanto à crueira, ela é torrada, no termino da farinhada, a qual alimenta as aves domesticas e ou ovinos. Por fim, a cinza, proveniente da queimada da lenha, é designada para adubar plantações como é o caso do plantio de jerimum que se fortalece, germinando assim um produto de qualidade.

No que tange o comércio da farinha, o gráfico 8 demonstra a percepção dos produtores da cidade, no qual $44 \%$ respondentes asseveraram que as vendas estão dentro das suas expectativas apesar das fragilidades do mercado. Ver gráfico abaixo:

\section{Percepção do Comércio da Farinha no RN}

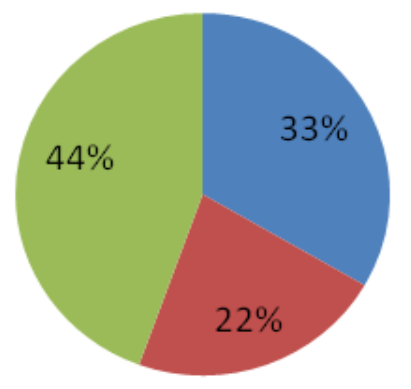

Ruim

- Regular

Bom

\section{Gráfico 8: Percepção do Comércio da Farinha de Mandioca no RN}

Diante da explicação dos demais respondentes o comércio da farinha não se encontra nas melhores fases, devido os produtores de outras regiões estarem ganhando uma fatia do mercado a partir da utilização do nome de Brejinho, por ser conhecida pela melhor farinha do nordeste como já foi mencionado. 
De acordo com eles a prefeitura municipal de Brejinho deveria buscar suporte para alavancar tanto a produção, como as vendas da farinha, já que tal prática é a referencia da cidade. Além disso, estes afirmaram que as vendas estão descontroladas, no qual sua representatividade positiva se apresenta de forma alternada.

Quanto aos $44 \%$, eles certificaram que para atender a demanda precisam comprar de outros produtores para abastecer seus pedidos, e também as casas de farinha estão cada vez mais se industrializando, o que retrata uma melhor produção a custos mais acessíveis.

Referente aos fornecedores destas casas de farinha, as principais cidades que cultivam a mandioca ficam concentrados em Lagoa Dantas, Lagoa de Pedra, Santo Antônio do Salto da Onça, Passa e Fica, Serra Caiada, Serrinha, Nova Cruz e em casos de escassez em Sapé na Paraíba. Já em Brejinho a plantação é muito pouca, apenas os donos de pequenas casas de farinha ainda plantam a fim de suavizar seus custos.

As produções são destinadas, além de Brejinho, apenas para regiões potiguares, como por exemplo, Parnamirim, Natal, Currais Novos, Santo Antônio, Lagoa do Mato, Lagoa de pedra, Nova Cruz, Montanhas, Canguaretama, Goianinha e outras cidades. Observando que $44 \%$ dos produtores vendem para atravessadores, por causa da sua inviabilidade em comercializar em outras regiões.

É necessário destacar que os entrevistados sentem dificuldades em expandir sua produção, uma vez que não possui um apoio para mudar seu quadro, um deles ressalva que na região sul do Brasil a farinha de mandioca tem uma participação significativa no mercado. Nesta região se compra muito a farinha de outros estados, inclusive de Pernambuco, a qual não possui uma qualidade tão estimada como a produzida em Brejinho.

No Brasil as Lojas Solidárias ainda são muito pouca, mas podem-se destacar algumas como: a Loja da Reforma Agrária em São Paulo, a Loja da Visão Mundial em Recife, a loja da Rede Sol em Curitiba que além da alternativa de comercialização para os pequenos produtores rurais e urbanos também divulgam a proposta e atuam na formação de um novo tipo de consumidor. (FRETEL E SIMONCELLI-BOURQUE, 2003, p. 72)

Outro aspecto de grande relevância é que existe ainda uma casa de farinha comunitária localizado no sítio tabuleiro, município da cidade, onde qualquer interessado pode produzir farinha. Esta iniciativa partiu da prefeitura de Brejinho junto ao Programa Nacional de Fortalecimento da Agricultura Familiar (PRONAF), tendo em vista que um dos entrevistados costuma utilizá-la para fabricar farinha, com o intuito de minimizar seus custos. É importante elencar que a produção desta casa de farinha não faz parte da pesquisa.

Isso se torna uma vantagem promissora para implantar a prática estudada, devido a casa ser comunitária, pois facilita a integração da comunidade cada vez mais na produção e na economia da cidade. Podendo melhorar as condições daqueles que podem estar desempregado. No que tange os fatores que interferem no comportamento dos clientes, o gráfico 11 mostra tal panorama. 


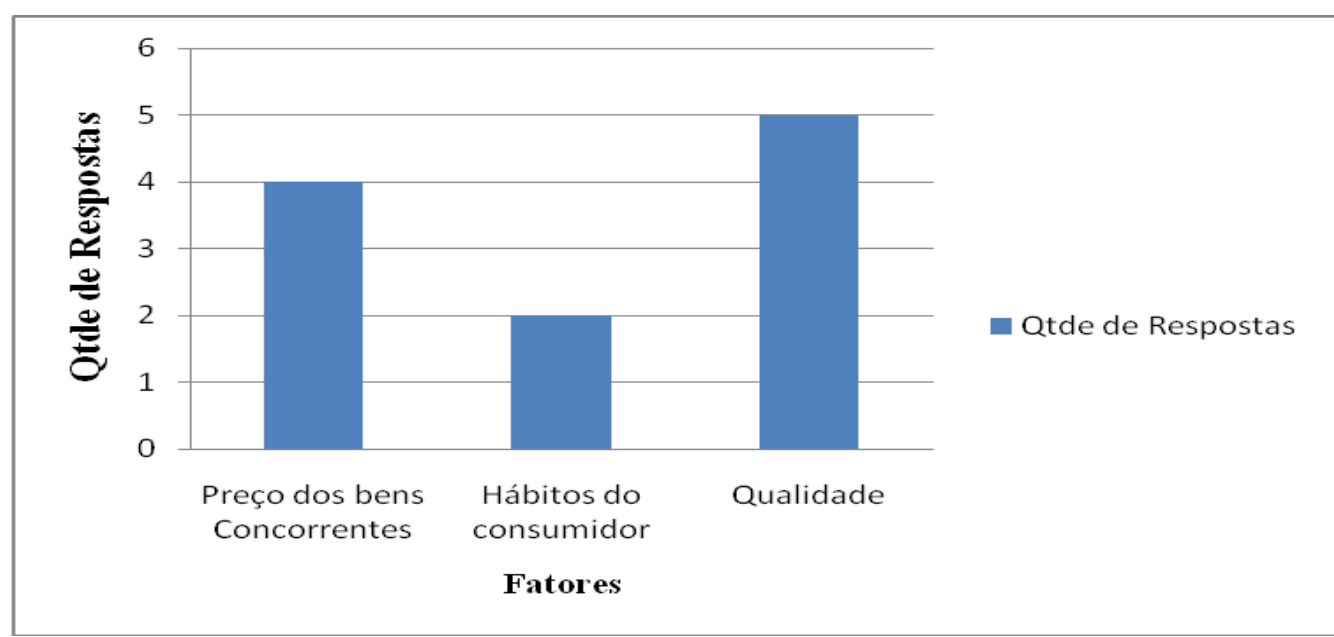

\section{Gráfico 11: Fatores Intervenientes no Comportamento do Consumidor}

Percebe por meio deste quadro que, a qualidade, é valorizada pelos consumidores a cima de qualquer outro fator. Outro ponto relevante é o preço dos bens concorrentes que ficou acima do hábito de consumir a farinha, demonstrando assim que eles oferecem qualidade a um preço competitivo.

Referente ao comércio justo apenas $1 \%$ dos entrevistados declarou já ter conhecido a prática, por meio de reportagens eletrônicas, já quanto aos outros nunca ouviram sobre, nem tinham idéia do que o definia. Todavia eles alegaram que as vantagens que este comércio poderia trazer a produção de farinha seria a criação de postos de trabalho, a melhoria na qualidade de vida dos vinculados e da comunidade, e o desenvolvimento produtivo do setor.

Diante desta indagação, um deles demonstrou que para isso ocorrer deve organizar uma reunião entre todos os produtores junto a autoridades para conscientizar-los a buscar programas que melhore o comércio farinheiro. Isso é uma questão relevante, pois atualmente o governo oferecendo muitos incentivos para que desenvolva a economia do país. Já ao se perguntar sobre uma possível união entre todos os produtores, os respondentes apresentaram à seguinte resposta, a qual está exposta no gráfico 12:

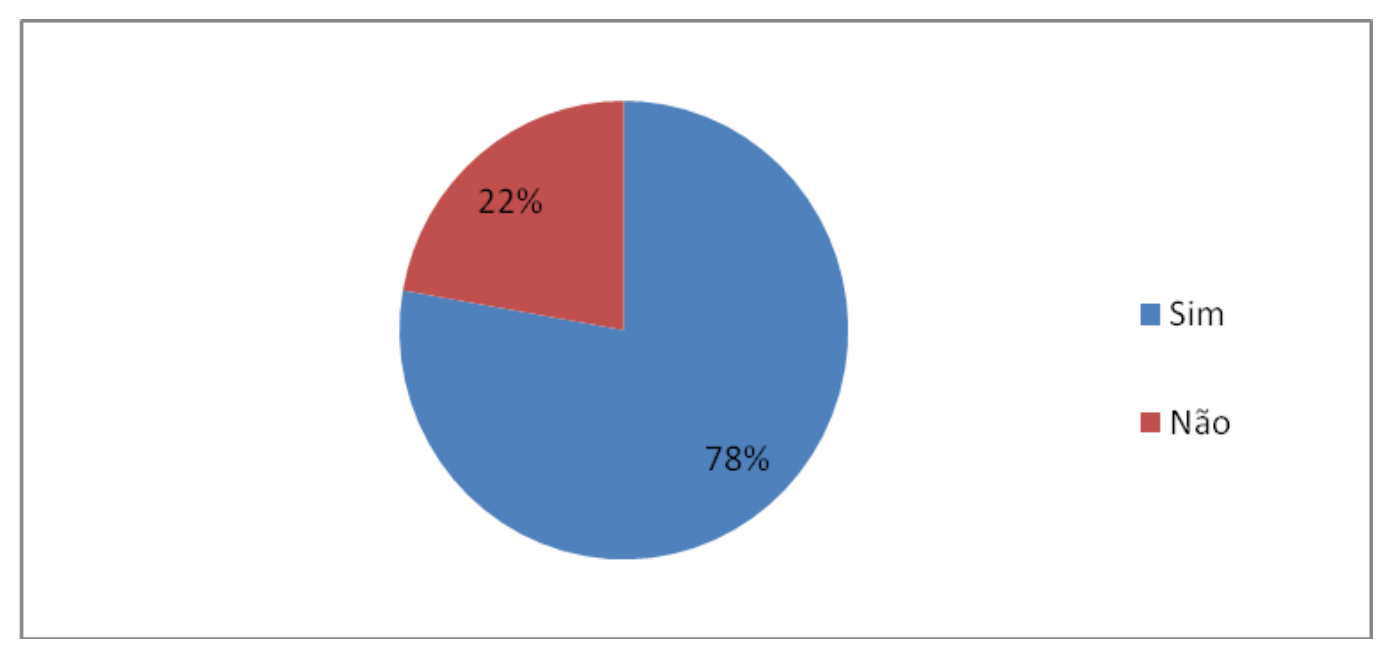

Gráfico 12: Opinião Sobre uma Possível união 
Percebe-se aqui que a maioria deles tem o interesse de se unir para formar uma associação ou cooperativa, pois segundo eles seria uma maneira de fortalecer o setor produtivo da cidade, porém a dificuldade estava em chegar a essa finalidade. Já os $22 \%$ apontaram não possuir interesse, por não ter coragem de adentrar em negócio como este. Entretanto, diante de todos os parâmetros já explorados, os donos das fábricas de farinha avaliaram a prática de comércio justo como o seguinte:

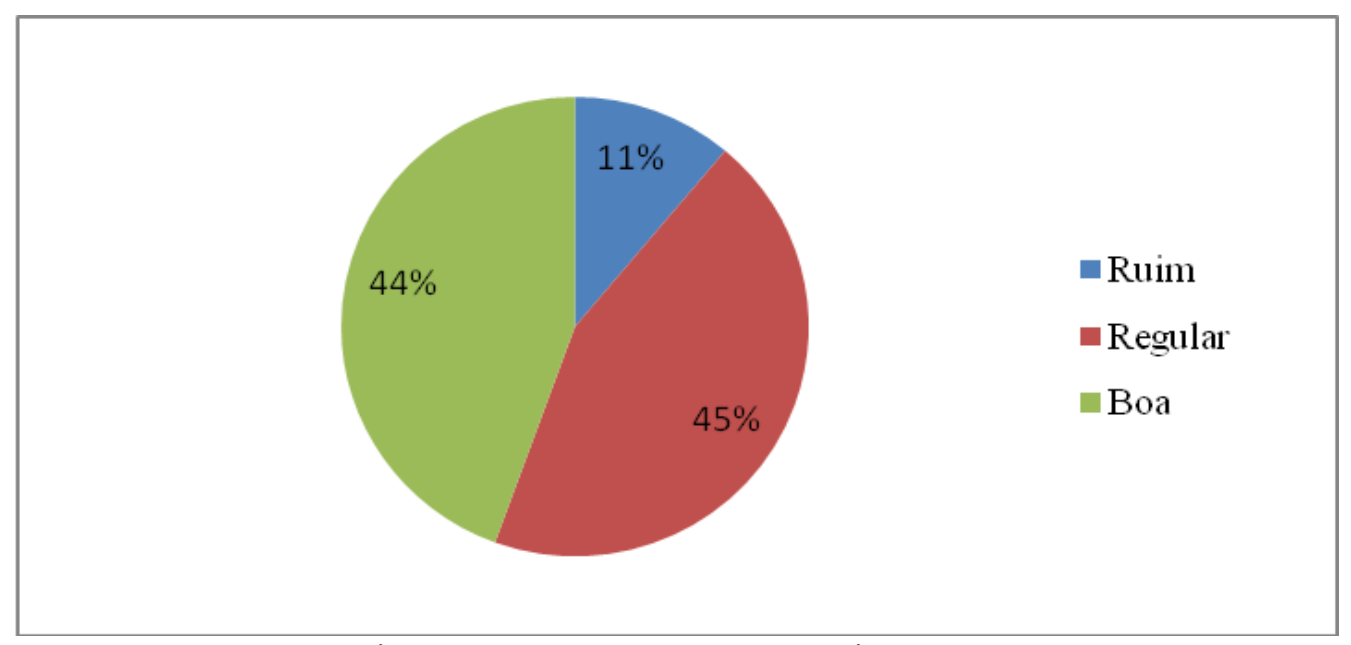

\section{Gráfico13: Avaliação do Comércio Justo}

A partir destes estudos percebe-se que o comércio justo foi a princípio bem aceito entre os produtores da cidade, uma vez que possibilita melhores condições de vida para todos. Tendo em vista que seria um projeto capaz de desenvolver a produção, como também uma maior divulgação da cidade e do produto.

Quanto o comércio exterior, a farinha já faz parte das exportações brasileiras, onde está industrializando o setor desde o cultivo até o processo final do produto, com o objetivo de vendê-los a um grau de qualidade excelente no comércio internacional.

De acordo com a Secretaria de Estado de Agricultura, Pecuária e Abastecimento (2008), a Parasol é um exemplo do setor. Tendo em vista que as exportações de modo geral do produto no estado de Minas Gerais movimentou uma receita de US\$ 3,4 mil no período de janeiro e fevereiro de 2008.

Conforme o NCM (11062000) de farinhas, suas exportações foram destinadas no ano de 2008 principalmente para Portugal e os Estados Unidos, os quais têm um valor FOB superior a US\$ 400.000. Por meio dos dados elencados no gráfico abaixo, percebe-se a insignificância do Mercado Comum do Sul (MERCOSUL) nas exportações do produto, onde apenas o Uruguai realiza tal intercâmbio. 


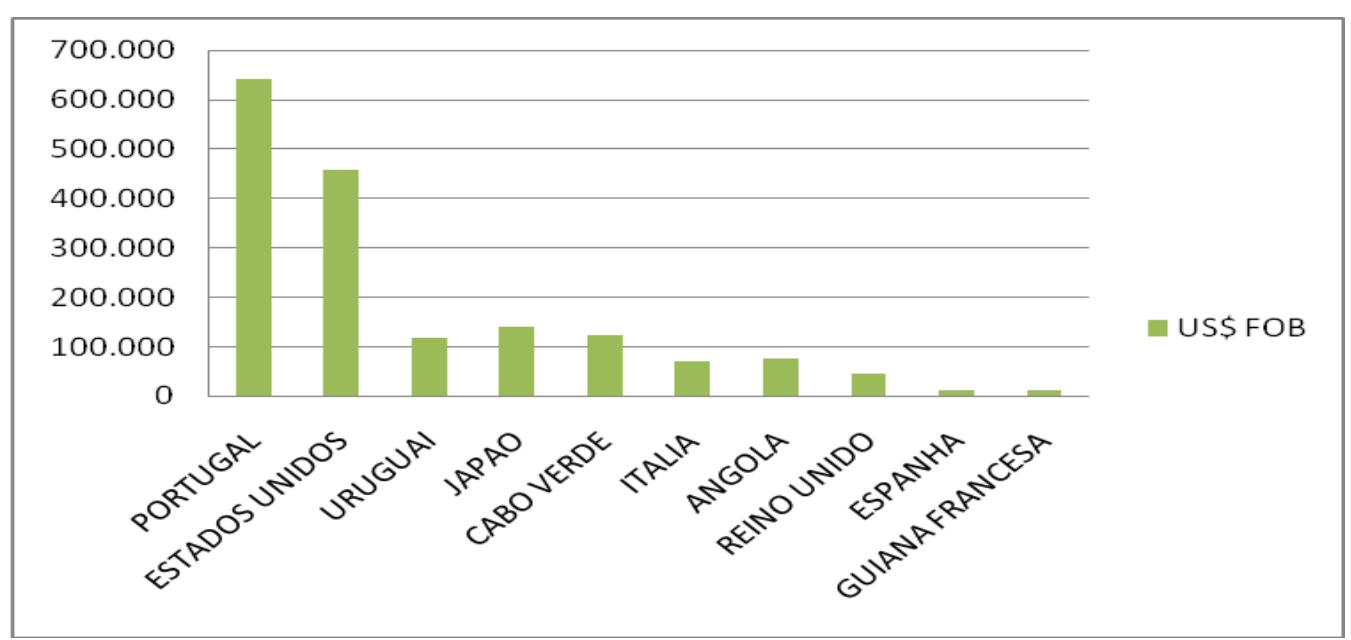

Gráfico 14: Potenciais Importadores

Para alcançar esse mercado é preciso está atento a eventos que permeiam o meio, pois a participação em feiras, rodadas de negócios são mecanismos essenciais para divulgar o produto, como também conhecer possíveis compradores. Com isso, ele é capaz de trocar informações tanto com compradores de outras regiões brasileiras, quanto estrangeiros.

O MDA afirmou que, durante a II Feira Nacional da Agricultura Familiar e Reforma Agrária, reuniram-se expositores e comerciantes de varios lugares que junto a estes estavão os fabricantes de farinha de mandioca. Além disso, eles participaram da rodada de negócios que contou com a presença comerciantes da Turquia, França e Itália.

A partir destes aspectos, as casas de farinha podem destacar no mercado, uma vez que elas tem capacidade de atender as exigencias legais, sociais e ambientais. Pois as empresas que aderem a responsabilidade social ganham destaque cada vez mais no merdado nacional e internacional. Tendo em vista que a prática do comércio justo na Europa está se tende a crescer e incentivar os pequenos produtores a desenvolverem seus produtos.

\section{CONSIDERAÇÕES FINAIS}

A prática do comércio justo no mundo se encontra com uma expansão estimável, pois pequenos empreendimentos estão ganhando força no mercado, uma vez que estão comercializando seus produtos com o selo do fair trade. Esta iniciativa chegou ao Brasil, trazendo benefícios consideráveis ao país, onde já conseguiu desenvolver pequenas comunidades que estavam marginalizadas no comércio.

Diante disso, a globalização ajudou a detectar práticas comerciais que garantem atualmente o sustendo de muitas famílias, as quais vão além das suas perspectivas quando se adéquam as exigências no fair trade, pois após atestá-la consegui inserir seus produtos no mercado com mais facilidade, atingindo até o exterior.

Logo, a inserção desta prática no Rio Grande do Norte ainda encontra-se pequeno, porém o estado possui uma gama de alternativas mercadológicas capaz de mostrar grandes potenciais no mercado. um exemplo disso são as pequenas famílias potiguares que têm 
capacidade de produzir artigos de qualidades que podem contornar sua economia e sua vida.

A partir do que foi elencado, o pesquisador concluiu que a cidade de Brejinho, a qual está localizada no RN tem capacidade de se destacar mais a farinha de mandioca no comércio com o selo do fair trade, desde que ele se adéqüe a algumas exigências ambientais e legais que o país determina.

Pois durante a produção da farinha diversos mecanismos são análogos as práticas do comércio justo, dentre eles a esfera ambiental, onde só apenas algumas casas de farinha de mandioca não aproveitam o resíduo mais tóxico que é a manipueira. Ela é usada para alimentar os bovinos, além de servir para adubar plantações, todavia os outros vestígios são todos usados para alimentar animais, geralmente domésticos.

Tais aspectos são muito importantes no que tange o comércio justo, pois os dirigentes das casas de farinha estão atendendo suas demandas sem agredir tanto o meio ambiente. Com isso, desde que sejam mais contornados, a prática produtiva da farinha podem atender as exigências do comércio estudado.

No que se refere à possibilidade de junção dos produtores, o pesquisador conclui que é preciso uma forte conscientização para isso ocorrer, tendo em vista que eles estão ficando em desvantagem devido fábricas de outras regiões aderirem o nome Brejinho na marca de seu produto.

Isso faz com que o consumidor se confunda no ato da sua compra, associando a marca com qualidade, uma vez que Brejinho é conhecido como a melhor farinha do estado. Porém, em alguns casos a farinha não leva uma qualidade tão estimável, logo prejudica os produtores brejinenses. Necessitando de buscar a indicação geográfica do produto para minimizar está situação.

Em relação aos aspectos legais as casas de farinha não obedecem como é devido, uma vez que não possuiu uma estrutura financeira capaz de atender todos os requisitos trabalhistas para melhorar as condições de vida dos empregados. Pois foi verificado que diante do quadro de empregados neste ramo, apenas duas pessoas têm sua carteira de trabalho assinada, as quais trabalham como gerentes da fábrica em que está empregada.

Além disso, a participação das mulheres são muito relevantes no processo da farinha de mandioca, no qual é necessário que raspe a mandioca para poder transforma-lá em massa, e assim começar o procedimento de secamento desta para finalizar em uma farinha.

No âmbito do comércio justo, isso é relevante para a inclusão social das mulheres na produção, pois as mulheres em pequenas regiões, na maioria das vezes encontram desempregadas, as quais estão apenas trabalhando em seu lar. Contudo, as concepções deste comércio podem vir a contribuir positivamente para desenvolver este quadro.

Porém existe também um baixo estima com relação ao trabalho no processo de mandioca, o qual não se é priorizado mais como alternativa de trabalho, pois a partir das iniciativas governamentais, como bolsa família, os membros das pequenas famílias estão abandonando trabalhos como este. 
É importante ressaltar que dentro das casas de farinha não se encontra mais crianças nem adolescentes, devido às exigências legais e o apoio municipal na adoção de programas que tiraram eles das ruas ou do meio de trabalho de seus pais. Facilitando assim, para os produtores e os empregados, principalmente as mulheres que antigamente não tinham com quem deixar seus filhos. Além disso, nota-se a relevância as seguintes sugestões para aderir o comércio justo e atingir o comércio internacional:

a) Inserção das normas da segurança e medicina do trabalho voltado para todos os funcionários;

b) Os produtores devem estar atentos e dispostos a melhorar sua produção para que possa atender as exigências do mercado exterior; e

c) Buscar parcerias com órgão do governo.

Valendo ressaltar que o mercado europeu é um dos mais aderentes dos produtos com o selo do fair trade, tendo em vista também que os parceiros comerciais dos exportadores brasileiros da farinha de mandioca estão concentrados na Europa. Contudo, para chegar neste estágio é preciso participar de eventos ligados ao segmento, pois geralmente os importadores tomam conhecimento dos produtos quando estão expostos em eventos como, por exemplo, rodadas de negócios, feiras e etc.

Diante disso, para ocorrer tal comercialização a partir do selo do comércio justo, os produtores da farinha precisam entender que esse caminho é um pouco demorado. Todavia, atendem as exigências do mercado internacional, ganhando reconhecimento, melhorias produtivas e financeiras, além de desenvolver sua comunidade.

Este comércio pode melhorar as condições socioeconômicas da cidade, como também do estado, uma vez que se ocorrer futuramente à exportação à balança comercial do estado pode ser favorecida a partir das vendas sucedidas. Outro aspecto relevante são os demais setores da região que possui também capacidade para se enquadrar na prática do comércio justo.

\section{REFERÊNCIAS BIBLIOGRÁFICAS}

1. BRASIL. Decreto lei n. ${ }^{\circ} 5.452$, de 01 de maio de 1943. Dispõe a consolidação das leis do trabalho. Disponível em: <http://www.planalto.gov.br/ccivil/DecretoLei/Del5452.htm> Acesso em: 11 nov. 2008.

2. $\quad$ Decreto $\mathrm{n}^{\circ} 5.764$ de 16 de dezembro de 1971. Dispõe a política nacional de cooperativismo. Disponível em: 〈http://www.planalto.gov.br/CCIVIL/leis/L5764.htm> Acesso em 28 nov. 2008.

3.

Decreto $\mathrm{n}^{\circ} 6.514$ de 22 de dezembro de 1977. Dispõe segurança e medicina do trabalho. Disponível em: < http://www.planalto.gov.br/CCIVIL/leis/L6514.htm> Acesso em: 22 nov. 2008

4.

Decreto $\mathrm{N}^{\circ} 8.069$ de 13 de julho de 1990. Dispõe o estatuto da criança e do adolescente. Disponível em: <http://www.planalto.gov.br/ccivil/LEIS/L8069.htm>

Acesso em: 28 nov. 2008 
5. BRASIL. Ministério do desenvolvimento agrário. Produtos orgânicos são os mais procurados na rodada de negócios: apresentação. Brasília, 2006.

6. CARVALHO, Vilson Sérgio de. Educação ambiental e desenvolvimento comunitário. Rio de Janeiro: WAK, 2002.

7. COELHO, Fábio Ulhoa. Manual de direito comercial: direito de empresa. 18. ed. São Paulo: Saraiva, 2007.

8. CUSTÓDIO, André Viana; Annoni, Danielle (cord). Direitos humanos e poder econômico: conflitos e alianças. Curitiba: Juruá, 2005.

9. DARCANCHY, Mara Vidigal. Responsabilidade social da empresa. Disponível em: <http://jus2.uol.com.br/doutrina/texto.asp?id=7989 >. Acesso em: 28 nov. 2008.

10. FERRARI, Glayson. Um pouco mais de comércio justo. Disponível em: $<$ http://www.fbb.org.br/portal/pages/publico/expandir.fbb?codConteudoLog=5143>. Acesso em: 29 out. 2008

11. FRETEL, Alfonso Cotera; SIMONCELLI-BOURQUE, Eloïse. O comércio justo e o consumo ético. Rio de Janeiro: DP\&A, 2003.

12. GIL, Antônio Carlos. Métodos e técnicas de pesquisa social. 5. ed. São Paulo: Atlas, 2006.

13. INSTITUTO BRASILEIRO DE GEOGRAFIA E ESTATÍSTICA. Rio Grande do Norte: Brejinho. Disponível em: <http://www.ibge.gov.br/cidadesat/topwindow.htm?1> Acesso em: 01 de nov. 2008.

14. JULIÃO, Valdir. Comércio justo" chega ao RN. 2008. Disponível em: <http://tribunadonorte.com.br/noticia.php?id=77746>. Acesso em: 10 nov. 2008

15. MAIA, Lerson Fernando dos Santos; OLIVEIRA, Marcos Vinicius de Faria. Trabalhos acadêmicos: princípios, normas e técnicas. Natal: CEFET/RN, 2006.

16. MINAS GERAIS (Secretaria). Secretaria de estado de agricultura, pecuária e abastecimento. Minas quer reforçar produção de mandioca: estado exporta farinha de mandioca para a Europa. Brasília, 2008. Disponível em: <http://www.portaldoagronegocio.com.br/conteudo.php?id=21697>. Acesso em: 18 maio 2009.

17. MOTA, José Aroudo. O valor da natureza: economia e política dos recursos ambientais. Rio de Janeiro: Garamond, 2006.

18. OLIVEIRA, Elvira Fernandes de Araújo; FILGUEIRA, Maria da Conceição Marciel. Primeiros passos da iniciação científica. Mossoró: Fundação Vingt-Um Rosado, 2004

19. PEGADO, Erika Araújo da Cunha. Impactos da legislação ambiental brasileira na exportação de camarão: um estudo com exportadores de camarão do Rio Grande do norte. In: ENCONTRO NACIONAL SOBRE GESTÃO EMPRESARIAL E MEIO AMBIENTE, 9., 2007, Curitiba. Anais eletrônicos... Curitiba: ENGEMA, 2007. Disponível em: <http://engema.up.edu.br/arquivos/engema/pdf/PAP0071.pdf >. Acesso em: 02 nov. 2008

20. POTENCIAL econômico Disponível em: <http://www.conhecaorn.com.br/potencialeconomico.php>. Acesso em: 10 nov. 2008. Sem paginação. 
21. RINCÓN, Jorge et al. Termo de referencia sebrae para o comércio justo. SEBRAE, Brasília: 2005.

22. RIBEIRO, Sônia Regina de Macêdo; SOUZA, Washington José de. Responsabilidade Social: Visões e Perspectivas de Empresários do Segmento Industrial do Rio Grande do Norte. In: ENCONTRO NACIONAL DE GESTÃO EMPRESARIAL E MEIO AMBIENTE, 10., 2008, Porto Alegre. Anais... Porto Alegre: ENGEMA 2008.

23. SCHMITT, Karin; LEISING, Klaus M. Ética empresarial: responsabilidade global e gerenciamento moderno. Rio de Janeiro: Vozes, 2001.

24. SCHNEIDER, Johann Wolfgang. Pesquisa mundial de comércio justo. 2. ed., SEBRAE, Brasília. Virtual Books: 2007. Disponível em : <http://201.2.114.147/bds/BDS.nsf/0D9F6C222DEF277B8325739100684DDA/\$File/ NT000372D6.pdf>. Acesso em: 24 nov. 2008.

25. SERVIÇO DE APOIO ÀS MICROS E PEQUENAS EMPRESAS. O aproveitamento sustentável da rama da mandioca e da manipueira. 2008. Disponível em: http://www.biblioteca.sebrae.com.br/bds/BDS.nsf/8F3BDF496FDA769783257487005 32E16/\$File/NT00038B42.pdf. Acesso em: 01 mar. 2009. Não paginado.

26. SILVA, Roberto Dias de. Direito Constitucional: temas atuais. São Paulo: Método, 2007.

27. VIEIRA, Liszt. Cidadania e globalização. Rio de Janeiro: 4. ed Record, 2000.

28. VERENHITACH, Gabriela Daou. O comércio justo como prática cooperativista e solidária - possibilidade de equilíbrio nas relações comerciais internacionais e desenvolvimento econômico-social. In: JORNADAS DE JOVENS PESQUISADORES DA ANGM, 14., 2006, Campinas. Anais eletrônicos... Campinas: Unicamp, 2006. Disponível $<$ http://www.cori.unicamp.br/jornadas/completos/UFSM/O\%20COMERCIO\%20JUST O\%20COMO.doc >. Acesso em: 18 out. 2008. Não paginado. 